\title{
Reacciones adversas cutáneas severas a medicamentos: estado del conocimiento
}

\author{
Severe cutaneous adverse drug reactions: state of knowledge
}

\author{
Ana M. Villa-Arango MD', Ana M. Acevedo-Vásquez MD², \\ Ricardo Cardona-Villa MSc ${ }^{3}$
}

\begin{abstract}
Resumen: las reacciones adversas a medicamentos afectan de manera global entre el $10 \%$ y el $20 \%$ de los pacientes hospitalizados y el $7 \%$ de los pacientes ambulatorios. Aproximadamente, uno de cada mil pacientes hospitalizados sufren reacciones adversas que amenazan la vida. Las reacciones adversas a medicamentos, denominadas como reacciones alérgicas (inmunológicas), se pueden agrupar según la clasificación de Gell y Coombs en: tipo I (mediada por IgE), tipo II (citotóxica), tipo III (por inmunocomplejos) y tipo IV (hipersensibilidad retardada o celular). Actualmente, las reacciones tipo IV se subclasifican según la célula efectora involucrada y sus correspondientes citoquinas. Estos subgrupos se definen como: tipo IVa (con activación del perfil Th1, los macrófagos como células efectoras y liberación de INF- $y$ y TNF- $\alpha$ ), tipo IVb (con activación del perfil Th2, los eosinófilos como células efectoras y liberación de citoquinas como la IL-5, la IL-4 y la IL-13), tipo IVc (con los linfocitos T citotóxicos como células efectoras y liberación de granzimas $B$ y perforinas) y tipo IVd (con los neutrófilos como células efectoras y liberación de CXCL8 y factor estimulante de colonias de granulocitos y macrófagos). La presente revisión se centra en la epidemiología, etiología, fisiopatología y manifestaciones clínicas de las reacciones adversas cutáneas severas
\end{abstract}

\footnotetext{
${ }_{1}^{1}$ Médica, residente en Alergología Clínica, Grupo de Alergología Clínica y Experimental (GACE). Medellín, Colombia. 2 Médica, especialista en Alergología Clínica. Alergóloga clínica, IPS Universitaria, Universidad de Antioquia. Grupo de Alergología Clínica y Experimental (GACE). Medellín, Colombia.

${ }^{3}$ Médico, especialista en Alergología Clínica, MSc en Inmunología. Docente titular, Universidad de Antioquia. Investigador senior, Director Grupo de Alergología Clínica y Experimental (GACE). Medellín, Colombia. Correspondencia: calle 64 \# 51 - 31, IPS Universitaria, sede Ambulatoria, Servicio de Alergología. Teléfono: 5744937090 ext. 30106. Correo electrónico: rcv2016udea@gmail.com

Conflicto de intereses: los autores declaran que no tienen conflicto de intereses Medicina \& Laboratorio 2016; 22: 539-562

Módulo 8 (Monitoreo de drogas), número 2. Editora Médica Colombiana S.A. $2016^{\circ}$ Recibido el 01 de diciembre de 2016; aceptado el 18 de diciembre de 2016
} 
a medicamentos como el síndrome de Stevens Johnson, la necrólisis epidérmica tóxica, el síndrome DRESS y la pustulosis exantemática generalizada aguda (PEGA); además de un abordaje terapéutico en cada una de estas enfermedades.

Palabras clave: hipersensibilidad, hipersensibilidad a las drogas, efectos colaterales y reacciones adversas relacionados con medicamentos.

Abstract: Adverse drug reactions affect globally between $10 \%$ to $20 \%$ of hospitalized patients and 7\% of outpatients. Approximately one in 1,000 hospitalized patients suffer life-threatening adverse reactions. Adverse reactions to drugs, called allergic reactions (immunological), can be grouped according to the Gell and Coombs classification: type I (IgE mediated), type II (cytotoxic), type III (by immunocomplexes), and type IV (delayed or cellular hypersensitivity). Currently type IV reactions are subclassified according to the effector cell involved and its corresponding cytokines. These subgroups are defined as: type IVa (activation of Th1 profile, effector cell macrophages, and release of INF- $\gamma$ and TNF- $\alpha$ ); type IVb (Th2 profile activation, effector cell eosinophil, and release of cytokines such as IL-5, IL-4 and IL-13); type IVC (effector cell cytotoxic $T$ lymphocytes and release of granzymes $B$ and perforins); and type IVd (effector cell neutrophil and release of CXCL8 and granulocyte-macrophage colony-stimulating factor). The present review focuses on the epidemiology, etiology, pathophysiology and clinical manifestations of severe cutaneous adverse drug reactions such as Stevens Johnson syndrome, toxic epidermal necrolysis, DRESS syndrome, and acute generalized exanthematous pustulosis, as well as a therapeutic approach in each of these diseases.

Key words: Hypersensitivity, drug hypersensitivity, drug-related side effects and adverse reactions.

Villa-Arango AM, Acevedo-Vásquez AM, Cardona-Villa R. Reacciones adversas cutáneas severas a medicamentos: estado del conocimiento. Medicina \& Laboratorio 2016; 22: 539-562.

$\mathrm{E}^{\mathrm{n}}$ n los servicios de salud se han introducido nuevos medicamentos para mejorar la calidad de vida y los resultados de los pacientes. Muchos de estos agentes terapéuticos se usan de forma crónica y asociados a otros de ellos [1], lo que contribuye al aumento en la presentación de reacciones adversas que se manifiestan predominantemente en la piel [2]. Estas reacciones pueden ir desde manifestaciones triviales, como erupciones maculopapulares, hasta reacciones severas que amenazan la vida, como la necrólisis epidérmica tóxica y el síndrome de Stevens Johnson. El impacto de estas reacciones es significativo en términos de costo en los servicios de salud y de calidad de vida de los pacientes [3].

Las reacciones adversas a medicamentos afectan de manera global entre el $10 \%$ y el $20 \%$ de los pacientes hospitalizados y el $7 \%$ de los pacientes ambulatorios. 
Aproximadamente 1 de 1.000 pacientes hospitalizados sufren reacciones adversas que amenazan la vida [4]. Pese a que la frecuencia de las reacciones adversas severas a medicamentos es baja, tienen un impacto en la salud pública por sus altas tasas de mortalidad ( $20 \%$ al $25 \%$ en general, $5 \%$ para el síndrome de Stevens Johnson y $30 \%$ al $50 \%$ para la necrólisis epidérmica tóxica) [5], que causan frecuentes incapacidades para el paciente sobreviviente y dificultades en la elección de medicación posterior por parte de los médicos [6].

Las reacciones adversas a medicamentos se han dividido, clásicamente, en reacciones tipo $A$ y tipo $B$; las primeras incluyen aquellas reacciones predecibles $y$ propias de los efectos farmacológicos del medicamento y las segundas a las reacciones impredecibles o no atribuidas a las propiedades farmacológicas del medicamento. Estas últimas ocurren en población susceptible y se han subdividido en reacciones de intolerancia, idiosincráticas e inmunológicas (alérgicas) [7].

Las reacciones adversas a medicamentos denominadas como reacciones alérgicas (inmunológicas) se pueden agrupar, según la clasificación de Gell y Coombs, en tipo I (mediada por IgE), tipo II (citotóxica), tipo III (inmunocomplejos) y tipo IV (hipersensibilidad retardada o celular) [7]. Actualmente, las reacciones tipo IV se subclasifican según la célula efectora involucrada y sus correspondientes citoquinas en: a) IVa, en la que se produce activación del perfil Th1, las células efectoras son los macrófagos y se libera INF- $\gamma$, TNF-a, b) tipo IVb, con activación del perfil Th2, célula efectora el eosinófilo y liberación de citoquinas como las interleuquinas IL-5, IL-4 e IL-13, c) tipo IVc, donde las células efectoras son los linfocitos T citotóxicos y se produce la liberación de granzimas $B$ y perforinas y d) tipo IVd, en la que las células efectoras son los neutrófilos y se da liberación de la quimioquina CXCL8 y el factor estimulante de colonias de granulocitos y macrófagos (GM-CSF) [8]. Las reacciones severas a medicamentos de tipo inmunológico se incluyen dentro del grupo de mecanismos de hipersensibilidad retardada.

El sistema inmune usa diferentes estrategias para combatir los agresores (virus, bacterias, parásitos). La respuesta natural a dichos agentes incluye varias vías efectoras, tanto simultáneas como secuenciales, que garantizan una defensa efectiva óptima; incluso la respuesta inmune ante antígenos simples proteicos puede producir anticuerpos tipo inmunoglobulina $\mathrm{E}(\mathrm{IgE})$ al igual que respuestas celulares mediadas por eosinófilos (tipo IVb). Los medicamentos estimulan, de forma simultánea, diversas funciones inmunológicas de la respuesta natural, lo que permite que la hipersensibilidad a medicamentos comprometa la interacción entre los mecanismos de hipersensibilidad [8].

Es importante destacar que la interacción que se produce entre los medicamentos y los mecanismos de hipersensibilidad tiene como protagonista a las células $T$ (véase figura 1), por ejemplo, la pustulosis exantematosa generalizada aguda (PEGA) 
compromete la interacción de las distintas funciones de las células $\mathrm{T}$ de forma simultánea (interacción entre tipos IVb, IVc y IVd) [8].

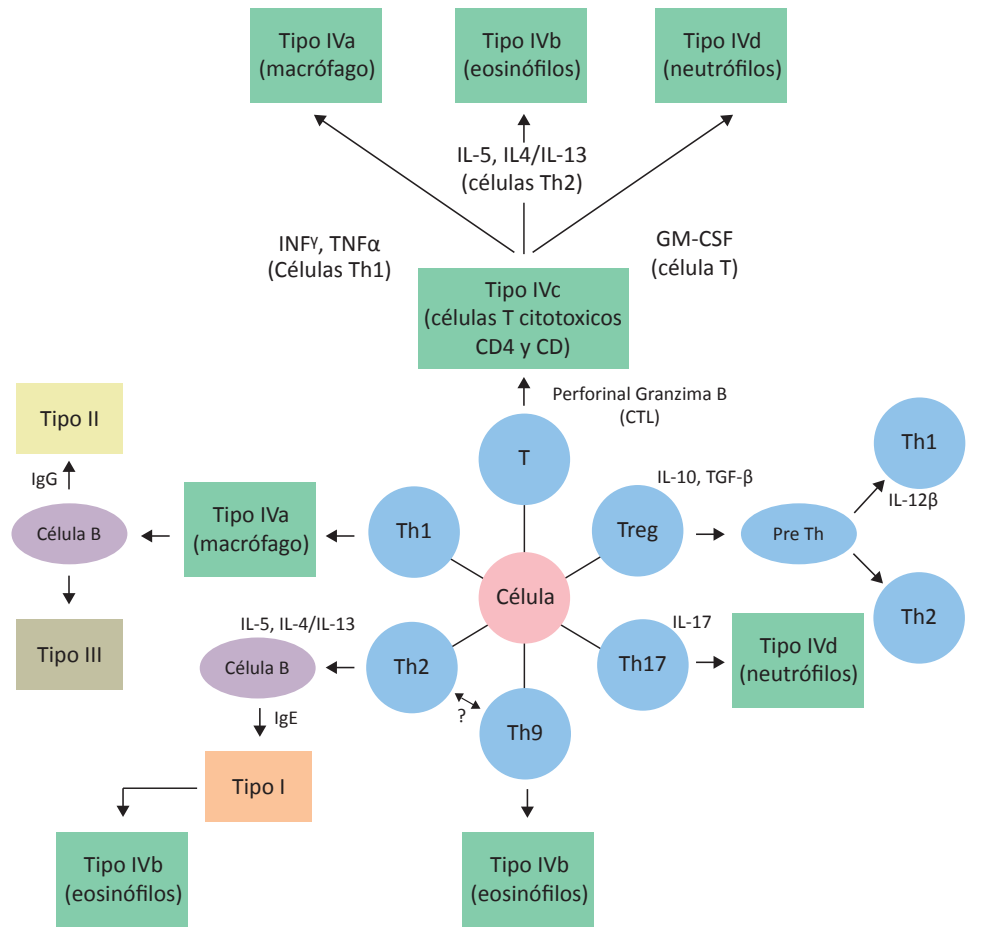

Figura 1. Interacción de las células T con todos los mecanismos de hipersensibilidad. Tomado de "Drug allergy to antibiotics: general review" por R. Cardona-Villa, 2015. Disponible: http://documentslide.com/ documents/drug-allergy-to-antibiotics-general-review-ricardo-cardona-villa-md-msc.html.Copyright ${ }^{\mathbb{2}} 2015$ por Documentslide.com

La presente revisión se centra en la epidemiología, la etiología, la fisiopatología y las manifestaciones clínicas de las reacciones adversas severas a medicamentos como el síndrome de Stevens Johnson, la necrólisis epidérmica tóxica, el síndrome de reacción a medicamentos con eosinofilia y síntomas sistémicos (DRESS) y la pustulosis exantemática generalizada aguda (PEGA); además, de un abordaje terapéutico en cada una de estas enfermedades.

\section{Síndrome de Stevens Johnson/necrólisis epidérmica tóxica}

\section{Generalidades}

El síndrome de Stevens Johnson y la necrólisis epidérmica tóxica son reacciones severas cutáneas que se producen, en su mayoría, en relación con el consumo o la aplicación de un medicamento. Estas reacciones se caracterizan por síntomas sistémicos como fiebre y malestar general asociados a lesiones mucocutáneas necróticas y con desprendimiento de la epidermis [9]. 
El síndrome de Stevens Johnson fue descrito por primera vez en 1922 en dos niños de siete y ocho años que presentaban «erupción mucocutánea generalizada con fiebre, estomatitis severa, conjuntivitis purulenta y necrosis extensa de la mucosa» [10]. Más tarde, el término de Stevens Johnson definió una enfermedad severa mucocutánea con un curso prolongado y potencialmente letal que en la mayoría de los casos era inducida por medicamentos y que debía distinguirse del eritema multiforme mayor [11].

La necrólisis epidérmica tóxica fue descrita por Ruskin en 1948 y luego nuevamente por Lyell en 1956. Este último describió cuatro pacientes con una erupción que se acompañaba de desprendimiento de la epidermis, a la cual le dio el nombre que aún se encuentra vigente. Solo hasta que se hizo la publicación de estos casos se encontró una clara asociación con el uso de medicamentos [10]. Hoy en día se consideran al síndrome de Stevens Johnson y la necrólisis epidérmica tóxica como dos espectros de reacciones cutáneas severas epidermolíticas a medicamentos, que se diferencian únicamente en la extensión de superficie corporal comprometida [11].

\section{Epidemiología}

La incidencia del síndrome de Stevens Johnson y la necrólisis epidérmica tóxica se estima que se encuentra entre uno y dos casos por un millón de personas por año [12]. La distribución por género para estas dos entidades es similar (levemente mayor en mujeres), mientras que para la superposición síndrome de Stevens Johnson/ necrólisis epidérmica tóxica la preponderancia es de aproximadamente el 65\% para el sexo femenino [13]. La mortalidad es en promedio menor al $10 \%$ para el síndrome de Stevens Johnson, 22\% para la superposición síndrome de Stevens Johnson/ necrólisis epidérmica tóxica y $30 \%$ para la necrólisis epidérmica tóxica [12].

Ambas entidades se pueden presentar en pacientes de cualquier edad; sin embargo, en varios estudios la media de edad de afectación para el síndrome de Stevens Johnson varía entre los 25 y los 47 años, dependiendo de las series revisadas. Respecto a la necrólisis epidérmica tóxica tiende a ser en pacientes con mayor edad, con reportes de edad media entre los 46 y los 63 años [14,15]. En un estudio reciente (2016) se encontró como factor de riesgo para desarrollar el síndrome de Stevens Johnson y la necrólisis epidérmica tóxica tener una edad entre los 18 y los 39 años [16].

Las diferencias regionales en la incidencia son debidas a la prescripción de medicamentos, la carga genética (HLA) y a la coexistencia de diversas enfermedades, como la infección por el virus de la inmunodeficiencia humana (VIH) [17].

\section{Definiciones}

Síndrome de Stevens Johnson: entidad que compromete menos del $10 \%$ de la superficie corporal [17]. Se caracteriza por síntomas prodrómicos como adinamia y fiebre, seguido por una rápida aparición de máculas eritematosas o purpúreas 
que pueden ser dolorosas. Es posible encontrar ampollas y lesiones en la piel que progresan a necrosis, con posterior desprendimiento de la epidermis. La mucosa se encuentra afectada entre el $90 \%$ y el $100 \%$ de los pacientes, usualmente en dos o más sitios [12].

Superposición síndrome de Stevens Johnson/necrólisis epidérmica tóxica: se denomina de esta forma al compromiso de la superficie corporal mayor del $10 \%$ pero inferior al 30\%, con las mismas características previamente descritas para el síndrome de Stevens Johnson [12].

Necrólisis epidérmica tóxica: esta condición compromete más del 30\% de la superficie corporal [12]. El cuadro clínico se caracteriza igualmente por síntomas prodrómicos; sin embargo, se describen temperaturas típicamente más altas que en el síndrome de Stevens Johnson, generalmente superiores a $39{ }^{\circ} \mathrm{C}$, y mayor compromiso de las mucosas [18].

\section{Etiología}

Los medicamentos son el factor relacionado en el $80 \%$ de los casos del síndrome de Stevens Johnson y la necrólisis epidérmica tóxica. Un pequeño porcentaje se asocia a infecciones, entre ellas las de origen viral y las causadas por Mycoplasma pneumoniae $[13,19,20]$.

Los medicamentos más implicados y que tiene un riesgo mayor de inducir reacciones adversas severas como las presentadas en el síndrome de Stevens Johnson y la necrólisis epidérmica tóxica son las sulfonamidas antimicrobianas (p. ej. trimetropim sulfametoxazol, sulfazalazina), los antiepilépticos (p. ej. carbamazepina, fenitoína, fenobarbital), los antinflamatorios no esteroideos (p. ej. oxicam), el alopurinol, empleado para disminuir el ácido úrico en plasma y orina, y más recientemente la nevirapina, un agente antirretroviral, y la lamotrigina, un antiepiléptico [6].

\section{Susceptibilidad genética}

La identificación de factores genéticos asociados a la hipersensibilidad a medicamentos ha sido estudiada en varios grupos étnicos. En la población china se ha descrito una fuerte asociación entre la hipersensibilidad a medicamentos y los antígenos leucocitarios humanos (HLA; del inglés, Human Leukocyte Antigen), específicamente entre el HLA-B*1502/síndrome de Stevens Johnson y el consumo de carbamazepina. Esta relación se estima que tiene una razón de disparidad mayor que 1.000 [21]. Una segunda asociación se ha evidenciado entre el genotipo HLA-B*5801 y el alopurinol, las cual ha sido confirmada en diferentes estudios con una razón de disparidad mayor que 800 [22-26]. Diversas investigaciones han sugerido cierta asociación entre algunos tipos de HLA y un efecto protector contra el síndrome de Stevens Johnson y la necrólisis epidérmica tóxica como efecto del tratamiento con carbamazepina, entre los que se incluyen el estudio de Cheung 
y colaboradores (2013) [27], en el que se estableció una relación con el HLAB*1502 y una posible asociación protectora con el HLA-B*4001.

\section{Fisiopatología}

El síndrome de Stevens Johnson y la necrólisis epidérmica tóxica son debidos a una reacción de hipersensibilidad retardada cutánea que involucra a los linfocitos $T$ citotóxicos, las células NK (linfocitos asesinos naturales) y los linfocitos Th17, que produce una activación exacerbada de la secreción de moléculas inflamatorias que generan un daño severo en los queratinocitos [28]. El daño de los queratinocitos resulta en su apoptosis y posterior necrosis celular, por lo que los factores inductores de la apoptosis se consideran el punto central en la patogénesis de estas entidades [29]. En condiciones normales, la apoptosis celular se da a través de dos vías, la vía intrínseca o la vía extrínseca, que cuando ocurre de forma no controlada lleva a las manifestaciones clínicas previamente descritas para estas entidades [30].

Los metabolitos de los medicamentos pueden causar la apoptosis de los queratinocitos generalmente por la vía intrínseca a través de la inducción del daño mitocondrial, lo que produce un aumento en la producción de radicales de oxígeno que inducen la producción de citoquinas proinflamatorias como el TNF- $\alpha$, el cual genera, finalmente, un daño directo en los componentes celulares. La vía extrínseca involucra la interacción entre los receptores de muerte y sus ligandos, como el FAS y el ligando de FAS (FAS-L), y la producción de proteínas citotóxicas derivadas de este contacto, principalmente en los linfocitos citotóxicos y las células NK. La activación de estos linfocitos permite la liberación extracelular de los gránulos citotóxicos que contienen perforinas, granzimas y granulisina, y que ejercen en este contexto efectos citotóxicos directos sobre los queratinocitos. La granulisina puede causar mayor daño que las perforinas y las granzimas ya que causa un daño directo en la mitocondria [29].

En 2008, Chung y colaboradores [31] detectaron altas concentraciones de granulisina en las ampollas de pacientes con necrólisis epidérmica tóxica y liberación de la granulisina tanto en los linfocitos citotóxicos como en las células NK. Además, encontraron poca expresión de la granulisina en personas sanas o con otras enfermedades de la piel. Takahashi y colaboradores (2009) [32] realizaron un análisis de las células $\mathrm{T}$ reguladoras $\left(\mathrm{CD} 4^{+}, \mathrm{CD} 25^{+}, \mathrm{FoxP} 3^{+}\right)$obtenidas de sangre periférica de 11 pacientes con necrólisis epidérmica tóxica, en las que se encontró una función alterada. Estos hallazgos sugieren que la modificación en la función normal de estas células se relaciona con la severidad y el daño epidérmico.

Un punto fundamental en la fisiopatología del síndrome de Stevens Johnson y la necrólisis epidérmica tóxica es la presentación antigénica de componentes derivados de los medicamentos, que lleva a la activación de las células T [33] por tres diferentes mecanismos: 
- La hipótesis del hapteno-prohapteno: un metabolito o hapteno derivado de los medicamentos se une de forma covalente a un autopéptido, generando un nuevo compuesto antigénico que es procesado en una célula presentadora de antígenos para ser presentado a través del HLA al receptor de linfocitos T (TCR) para producir su activación. Este proceso es mediado por el sistema inmune innato [34].

- El concepto p-i: el medicamento se une de forma no covalente al HLA o al TCR, o raramente a ambos de forma simultánea, lo que facilita la interacción y resulta en la activación de las células T. Esta interacción con el HLA o el TCR es rápida y es independiente del metabolismo. La unión del medicamento resulta en un cambio en el complejo HLA-péptido-TCR y no requiere ningún cambio en el péptido [34].

- La hipótesis de la alteración del repertorio del péptido: el medicamento se une de forma no covalente al péptido ya unido al HLA, alterando el repertorio de este. Como la combinación del HLA y el autopéptido es nueva las células T circulantes no son tolerantes al nuevo antígeno, entonces se estimula su activación [34].

\section{Presentación clínica}

Los síntomas aparecen entre una y ocho semanas posterior al contacto con el medicamento implicado (en promedio 14 días) [12]. La reexposición puede resultar en un inicio temprano de los síntomas, tan rápido como 48 horas posterior al uso del agente sospechoso [35]. El síndrome de Stevens Johnson y la necrólisis epidérmica tóxica típicamente presentan síntomas prodrómicos inespecíficos, similares a los de un cuadro viral, generalmente entre uno y tres días antes de la aparición de las lesiones mucocutáneas. La sensibilidad en la piel, la fotofobia, el prurito conjuntival o la sensación de quemazón pueden ser síntomas tempranos en ambas condiciones. Las lesiones en piel inician como máculas bien definidas, con centro purpúreo, en diana atípicas, es decir, con un anillo edematoso, palpable, con dos zonas y bordes pobremente definidos [12].

Cerca del $50 \%$ de los casos pueden iniciar como un eritema difuso y se pueden acompañar de sensación de quemazón o parestesias en las lesiones [13]. La distribución de las lesiones son asimétricas y pueden iniciar en tórax, cara, palmas y plantas [12]. El cuero cabelludo generalmente no está comprometido. Las lesiones cutáneas rápidamente progresan a ampollas y a desprendimiento epidérmico, con signo de Nikolsky positivo. Las mucosas están comprometidas en más del $90 \%$ de los casos de síndrome de Stevens Johnson y necrólisis epidérmica tóxica [13].

Las lesiones conjuntivales se reportan en el $85 \%$ de los casos; se puede presentar desde hiperemia simple e inyección conjuntival hasta desarrollo de sinequias [36]. Es común el compromiso sistémico, con alteración en la función renal y hepática y asociado a uretritis, retención urinaria, complicaciones pulmonares como neumonía, edema pulmonar y bronquiolitis obliterante [13]. 


\section{Diagnóstico}

El diagnóstico del síndrome de Stevens Johnson y la necrólisis epidérmica tóxica es con base en un buen interrogatorio y examen físico, apoyado por hallazgos histológicos inespecíficos, tales como: infiltrado perivascular de mononucleares y linfocitos $T$, alteración de la unión dermoepidérmica y muerte de queratinocitos basales. Al progresar las lesiones se encuentra desarrollo de vesículas subepidérmicas y necrosis de todas las capas epidérmicas [18]. No obstante, el diagnóstico clínico no siempre es suficiente. En un estudio reciente (2016) se sugirió la realización de la biopsia de piel a todos los pacientes con sospecha de síndrome de Stevens Johnson y necrólisis epidérmica tóxica para excluir o confirmar otras condiciones o diagnósticos diferenciales [37].

La severidad del cuadro clínico del síndrome de Stevens Johnson y la necrólisis epidérmica tóxica no permite realizar retos ni pruebas intradérmicas con el medicamento implicado por el alto riesgo de inducir un segundo episodio. El uso de las pruebas de parche es controversial y aún no es aceptado como ayuda diagnóstica [38]. Hassoun-Kheir y colaboradores (2016) [39] utilizaron esta prueba para detectar los medicamentos implicados en las reacciones adversas cutáneas, la cual mostró una alta especificidad pero muy baja sensibilidad, con un mayor rendimiento para las reacciones causadas por antibióticos y anticonvulsivantes.

Nuevos métodos in vitro se están desarrollando para el estudio de la citotoxicidad específica por medicamentos [40]. Algunos de estos ensayos permiten identificar el riesgo individual de reacción antes de la administración del medicamento y otros se usan para identificar el agente involucrado en una reacción ya ocurrida. Para este último propósito los métodos más desarrollados son [41]:

- Test de transformación de linfocitos: método con baja sensibilidad y especificidad para los casos de síndrome de Stevens Johnson y necrólisis epidérmica tóxica [42].

- ELISpot: determina el número de células que liberan citoquinas y marcadores citotóxicos, después de su activación por el medicamento implicado o sus metabolitos [41].

- ELISA: para la detección de citoquinas y marcadores celulares, como el IFN-Y, la IL-10 y la IL-5, liberados al medio [41].

Además, existe una herramienta estadística que le permite al clínico identificar si el medicamento que el paciente estaba consumiendo está involucrado en la reacción. La herramienta ALDEN consiste en una serie de preguntas con una puntuación para cada una de ellas y, según el resultado final, se le adjudica la probabilidad de que un determinado medicamento está implicado en la reacción. Este formulario puede ser consultado en los buscadores virtuales para su aplicación [12]. 


\section{Diagnósticos diferenciales}

Los mayores diagnósticos diferenciales del síndrome de Stevens Johnson y la necrólisis epidérmica tóxica son enfermedades autoinmunes como la dermatosis IgA, el pénfigo bulloso y el síndrome de piel escaldada estafilocócico. Los síntomas clínicos son similares en estas entidades; sin embargo, la histología puede hacer la diferenciación. Otros diagnósticos diferenciales incluyen el eritema multiforme mayor y la pustulosis exantemática generalizada aguda [12].

\section{Tratamiento}

El tratamiento recomendado para el síndrome de Stevens Johnson y la necrólisis epidérmica tóxica consiste en suspender el agente causal y brindar cuidados de soporte [43]. Estos últimos son esenciales para el éxito del tratamiento. Dentro de estas medidas se destacan la remisión a una unidad de cuidados intensivos o unidad de quemados, el manejo conservador de la piel, la adecuada hidratación y la pronta definición de la vía nutricional. El compromiso ocular es usual, por lo que se debe realizar la interconsulta con oftalmología para un manejo óptimo [13].

Como terapia inmunosupresora se ha usado la ciclosporina, la cual se ha asociado con una rápida reepitelización y menor mortalidad cuando se usa a dosis de 3 $\mathrm{mg} / \mathrm{kg} /$ día durante 8 a 24 días; sin embargo, los datos que soportan su uso son insuficientes [12]. Los esteroides tienen propiedades antiapoptóticas, pero los resultados no han mostrado beneficio. La dosis usual es dexametasona intravenosa $1,5 \mathrm{mg} / \mathrm{kg} /$ día por tres días [9].

Como terapia antiapoptótica, y ante la presencia de autoanticuerpos dirigidos contra FAS, se ha usado inmunoglobulina humana a dosis de $1 \mathrm{~g} / \mathrm{kg} /$ día durante 3 a 4 días. No obstante, de acuerdo con Mehregan y colaboradores (2016) [44], los estudios hasta ahora realizados indican que ni los esteroides ni la inmunoglobulina humana tienen efectos significativos sobre la mortalidad en comparación con las medidas de soporte adecuadas.

Otra opción terapéutica es la plasmaféresis, cuyo reporte de resultado exitoso es hasta del $80 \%$ en la necrólisis epidérmica tóxica severa que no responde a medicamentos. El mecanismo de acción probable es la remoción de FAS-L [12]. Además, en los últimos años se ha utilizado infliximab en algunos casos graves de necrólisis epidérmica tóxica con respuestas prometedoras $[45,46]$; sin embargo, se requieren mayores estudios para confirmar su aplicación para esta enfermedad.

\section{Pronóstico y severidad}

El síndrome de Stevens Johnson y la necrólisis epidérmica tóxica son entidades severas que presentan tasas significativas de morbi-mortalidad. El promedio de mortalidad se reporta para el síndrome de Stevens Johnson entre el $1 \%$ 
y el $5 \%$, y para la necrólisis epidérmica tóxica entre el $25 \%$ y el $35 \%$; sin embargo, puede ser mayor en pacientes ancianos y en quienes tienen gran compromiso de su superficie corporal. Para estandarizar la evaluación de los pacientes, el riesgo y el pronóstico, se han propuesto diferentes sistemas de evaluación, donde el SCORTEN (del inglés, SCORe of Toxic Epidermal Necrosis) es actualmente el más utilizado. Esta puntuación tiene en cuenta los siguientes parámetros: edad, presencia de neoplasia maligna, taquicardia, superficie corporal inicial comprometida, valores de nitrógeno ureico, glucosa sérica y bicarbonato. La puntuación va de 0 a 7 y predice una mortalidad del 3,2\% en aquellos con una puntuación entre 0 y 1 , y de más del $90 \%$ para aquellos con una puntuación mayor que 5 [47].

\section{DRESS}

\section{Generalidades}

El síndrome de reacción a medicamentos con eosinofilia y síntomas sistémicos (DRESS; del inglés, Drug reaction with eosinophilia and systemic symptoms) o síndrome de hipersensibilidad inducido por drogas (DIHS; del inglés, Druginduced hypersensitivity syndrome) es una reacción adversa severa inducida por medicamentos. El proyecto internacional dedicado a la investigación de las reacciones adversas cutáneas severas (RegiSCAR; del inglés, European Registry of Severe Cutaneous Adverse Reactions (SCAR) to Drugs and Collection of Biological Samples) adoptó estos dos términos para definir a los pacientes que presentaban un aumento de los niveles de eosinófilos en sangre asociado a síntomas sistémicos tras la aplicación de un medicamento [48]. El acrónimo DRESS fue establecido por Bocquet y colaboradores en 1996 [49], con el que describieron un síndrome potencialmente fatal que tiene como características: erupción cutánea, fiebre, alteraciones hematológicas (eosinofilia y linfocitosis atípica) y compromiso multiorgánico. No obstante, este síndrome fue reconocido por primera vez en 1950 por Chaiken y colaboradores en un paciente que consumía anticonvulsivantes [50].

\section{Epidemiología}

El síndrome DRESS constituye la entidad más común de las reacciones severas a medicamentos, representando el $13 \%$ de ellas [51]. Se estima que la incidencia de este síndrome tiene un rango de 1 a 1.000 y 1 a 10.000 exposiciones a medicamentos [52,53]. Los adultos generalmente son los más afectados [52]. Aunque la incidencia no ha sido determinada se considera una entidad más común que el síndrome de Stevens Johnson. La tasa de mortalidad es del 5\% al 10\%, con base en estudios retrospectivos, donde la necrosis hepática representa la primera causa de muerte $[54,55]$. 


\section{Etiología}

Los medicamentos más implicados en el desarrollo de este síndrome son:

- Anticonvulsivantes aromáticos: carbamazepina, fenitoína y fenobarbital [53].

- Otros anticonvulsivantes: lamotrigina, felbamato, oxcarbazepina.

- Sulfonamidas y sulfonas: sulfasalazina, dapsona y trimetropima sulfametoxazol [54].

- Antinflamatorios: piroxicam, diclofenaco, celecoxib, naproxeno.

- Antidepresivos: fluoxetina, amitriptilina, bupropion [53].

- Agentes antimicrobianos: abacavir, terbinafina, nevirapina, nitrofurantoina, minociclina, linezolida, doxiciclina, metronidazol, piperacilina-tazobactam, ceftriaxona [53].

- Inhibidores de la enzima convertidora de angiotensina: captopril, enalapril [52].

Los casos reportados de DRESS de forma más consistente son debido a los anticonvulsivantes aromáticos para los cuales se estima una ocurrencia de 1 en cada 5.000 personas expuestas a estos medicamentos; las reacciones se desarrollan más comúnmente en personas de raza negra [56]. La reactividad cruzada entre estos medicamentos varía del $40 \%$ al $80 \%$ [48].

\section{Susceptibilidad genética}

Diversos estudios farmacológicos han demostrado una fuerte asociación entre los haplotipos del HLA y la susceptibilidad de desarrollar DRESS [57-59]. En la población China de la etnia Han el HLA-B 5801 ha demostrado una fuerte asociación con el riesgo de desarrollar DRESS en los pacientes que utilizan alopurinol [23]. También se ha vinculado el consumo de abacavir con el HLA-B* 5701 en la población europea y africana [60] y la carbamazepina con el HLA-B*0801, el HLA DRB1*0301 y el HLA-A*3101 en diferentes poblaciones étnicas $[58,59]$.

\section{Infecciones virales}

La posible relación entre el desarrollo del síndrome DRESS y la reactivación de las infecciones por el herpesvirus humano-6 (HHV-6) ha sido previamente demostrada [61]. En un estudio de 100 pacientes con DRESS el incremento de los títulos de anticuerpos contra el HHV-6 fue detectado en el $60 \%$ de los pacientes en un periodo de dos a cuatro semanas luego del inicio del cuadro clínico. Además, se detectó mediante reacción en cadena de polimerasa (PCR) una cantidad significativa de ADN del herpesvirus humano- 6 en las muestras de los pacientes y en aproximadamente el $30 \%$ de aquellos que presentaban incremento en los títulos de anticuerpos contra el herpesvirus humano-6, lo que indica que hay una replica- 
ción activa del virus en estos pacientes. Las recaídas de los síntomas también se relacionaron con la detección del ADN del herpesvirus humano-6, lo que sugiere que la reactivación viral contribuye a los fenotipos y severidad del DRESS [62].

Asimismo, se han reportado casos esporádicos donde no solo está involucrado el herpesvirus humano-6, sino otros virus de la familia de los herpes virus como el herpesvirus humano-7 (HHV-7), el virus del Epstein Barr y el citomegalovirus, los cuales se pueden reactivar durante el curso del DRESS [63].

\section{Fisiopatología}

El mecanismo exacto de desarrollo del DRESS es aún incierto, pero se sabe que hay tres componentes básicos que interactúan durante la reacción: a) alteración o deficiencia en el metabolismo de medicamentos, b) asociación con la reactivación de la familia de los herpes virus y c) predisposición étnica con algunos haplotipos del HLA [64].

Con respecto al primer punto se ha planteado que los individuos con mutaciones específicas en los genes que codifican para las enzimas implicadas en el metabolismo de medicamentos tienen un aumento del riesgo de desarrollar DRESS. Estos polimorfismos genéticos explican la distribución familiar de alguna de estas reacciones adversas y la posible predisposición racial (más casos en pacientes de raza negra). Las mutaciones en estas enzimas, especialmente la deficiencia o alteración de la epóxido hidroxilasa, genera la acumulación de metabolitos reactivos tóxicos, los cuales inducen activación de la respuesta inmune; además de una reactivación viral. El fenotipo de $\mathrm{N}$-acetilador lento es asociado igualmente con el desarrollo de DRESS [65].

La reactivación viral en el DRESS aún no está clara; sin embargo, hay dos hipótesis que ayudan a comprender mejor este fenómeno. La primera postula que el síndrome DRESS inicia como una reacción inmune a un medicamento en particular, que estimula a los linfocitos T de forma masiva, en cuyo contexto se puede reactivar el genoma viral preexistente. La segunda postula que la reactivación viral puede ocurrir, pero inicialmente es clínicamente indetectable; sin embargo, la estimulación de las células $T$ por el virus presenta una reactividad cruzada significativa con ciertos medicamentos, por lo que la exposición a estos se traduce en una expansión de células $T$ específicas para el medicamento y el virus que persiste a pesar de la suspensión del medicamento y está dado por la persistencia antigénica del virus [53].

La reactivación viral se caracteriza por producir señales de daño que estimulan la expansión de los linfocitos T CD8 ${ }^{+}$y CD4+ no específicos, los cuales van a conducir al desarrollo completo de todo el síndrome [66]. Lo anterior permite concluir que para que ocurra el DRESS se deben dar ciertas condiciones, tales como la 
utilización de medicamentos, la reactivación viral y la interacción de todo lo anterior con el sistema inmune [48].

Un estudio realizado por Hirahara y colaboradores (2010) [67] en individuos con DRESS demostró una disminución en el recuento total de linfocitos $B$ asociado a hipogamaglobulinemia, lo que indica que esta supresión del sistema inmune puede contribuir igualmente a la reactivación viral en estos pacientes. De manera similar, en el síndrome de DRESS se ha descrito que varias citoquinas proinflamatorias, entre ellas la IL-6 y el factor de necrosis tumoral (TNF), se encuentran aumentadas [66]. La activación eosinofílica y la cascada inflamatoria reportada en el DRESS son inducidas por la liberación de la IL-5 por parte de los linfocitos $\mathrm{TCD}^{+}$y $\mathrm{CD}^{+}$. Los linfocitos $\mathrm{T}$ reguladores inicialmente aumentan su número en circulación y en piel, pero luego disminuyen en paralelo con el deterioro funcional de los órganos del paciente $[65,68]$.

\section{Presentación clínica}

Las manifestaciones típicamente se desarrollan dos a ocho semanas después de iniciar el medicamento causal y pueden persistir a pesar del retiro de este [52]. La fiebre suele preceder a los síntomas cutáneos, los cuales son variables; sin embargo, el exantema morbiliforme es el más común y se caracteriza por ser difuso, pruriginoso, macular y en ocasiones con eritrodermia. Estas lesiones pueden progresar y comprometer gran parte de la superficie corporal y resultar en una dermatitis exfoliativa (véase figura 2) [53]. Los síntomas pueden estar acompañados de edema facial en el $50 \%$ de los casos [69].
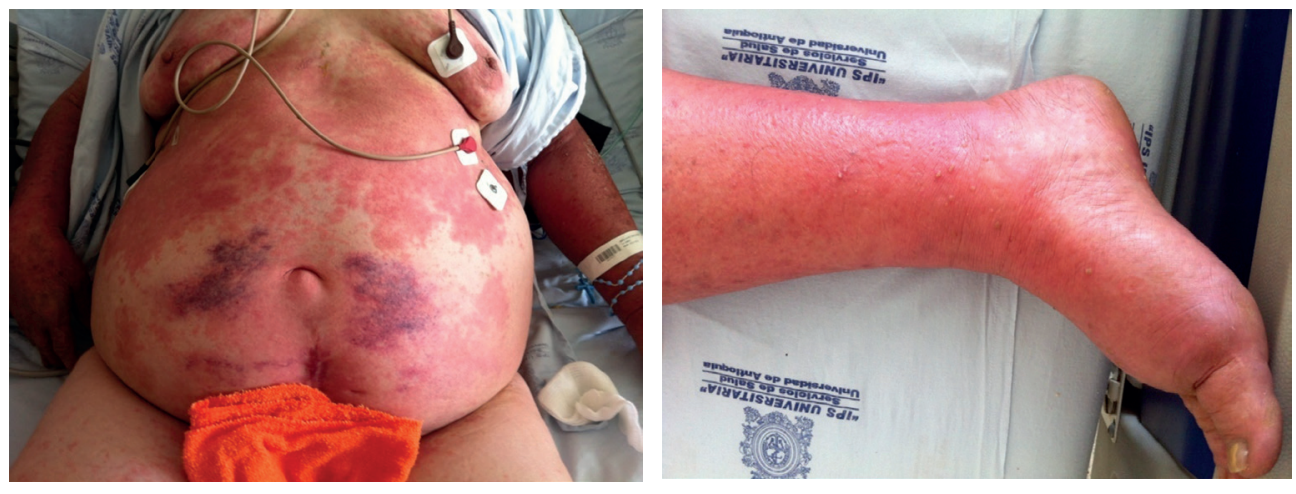

Figura 2. Paciente con síndrome de DRESS del servicio de Alergología Clínica de la Universidad de Antioquia. Medellín, Colombia.

Las alteraciones en las pruebas hepáticas y hematológicas, estas últimas consistentes en eosinofilia ( $30 \%$ de los casos) y linfocitosis atípica, explican el compromiso sistémico de esta entidad. La infiltración eosinofílica produce falla multiorgánica con daño de los órganos infiltrados, especialmente el riñón, el corazón, los pulmones y el páncreas [66]. 


\section{Diagnóstico}

Actualmente no existe un diagnóstico estandarizado. Antes de confirmar el DRESS se deben descartar otras condiciones como infecciones, procesos neoplásicos y desórdenes tanto autoinmunes como enfermedades del tejido conectivo [66]. Debido a las lesiones en piel de características variables el DRESS puede asemejarse a diferentes condiciones que hacen difícil el diagnóstico oportuno (véase figura 3) [53].
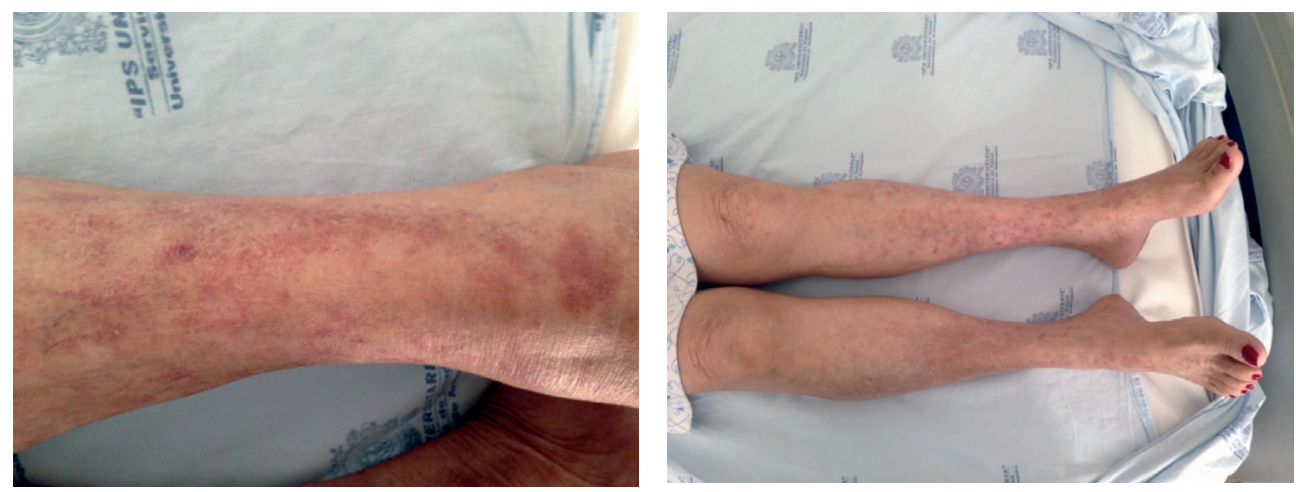

Figura 3. Paciente con síndrome DRESS por furosemida, la cual se reactivó luego de la resolución de los síntomas iniciales al tener contacto nuevamente con el medicamento. Diagnóstico diferencial urticaria vasculítica. Paciente del Servicio de Alergología Clínica de la IPS Universitaria, Universidad de Antioquia. Medellín, Colombia.

Los criterios diagnósticos propuestos se basan en los hallazgos clínicos y de laboratorio. Los paraclínicos y la biopsia pueden ayudar pero no siempre son específicos. Bocquet y colaboradores (1996) [49] propusieron los criterios diagnósticos iniciales los cuales incluyen: a) erupción por medicamentos, b) alteraciones hematológicas (eosinofilia y presencia de linfocitos atípicos) y c) manifestaciones sistémicas (adenopatías mayores de $2 \mathrm{~cm}$, elevación de enzimas hepáticas dos veces su valor normal, nefritis intersticial, neumonitis y carditis). La presencia de por lo menos tres criterios establece el diagnóstico. RegiSCAR aumentó los criterios y estableció que tres de cuatro criterios especiales deben estar presentes para establecer el diagnóstico de DRESS (véase tabla 1) [53].

Otros criterios diagnósticos propuestos son desarrollados por el Comité Japonés de Investigación de Reacciones Adversas Cutáneas Severas (J-SCAR; del inglés, Japanese Research Committee on Severe Cutaneous Adverse Reaction), en los que dan gran importancia al rol del HHV-6, que cuando está presente denominan el síndrome como síndrome de hipersensibilidad inducido por drogas (DIHS). Si los siete criterios se cumplen se denomina DIHS típico, si solo se cumplen cinco se denomina DIHS atípico (véase tabla 1) [65]. 


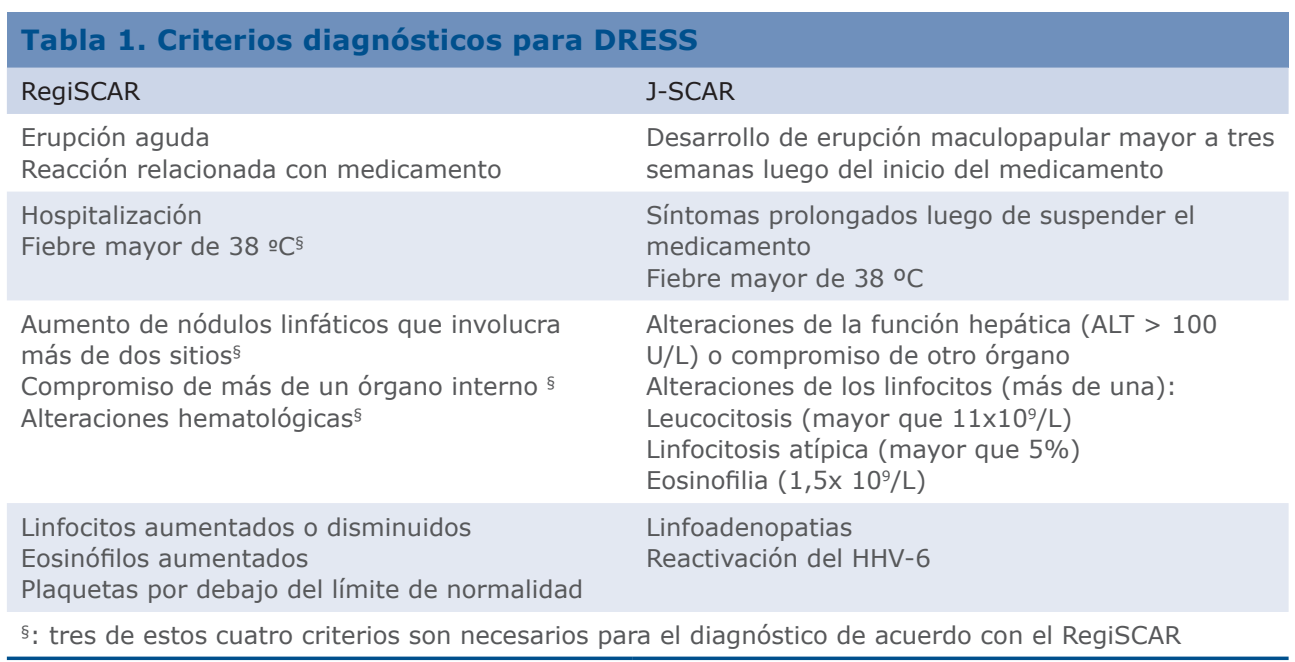

\section{Paraclínicos complementarios}

Se deben solicitar paraclínicos enfocados en apoyar el diagnóstico y descartar otras condiciones patológicas. Descamps y colaboradores proponen solicitar al momento de la admisión las siguientes pruebas: hemoleucograma, ALT, AST, bilirrubina total, fosfatasa alcalina, creatinina, depuración de creatinina, proteínas en orina de 24 horas, conteo de eosinófilos en orina, creatina fosfoquinasa (CPK), lactato deshidrogenasa (LDH), ferritina, triglicéridos, calcio, glicemia, tiempos de coagulación, lipasa, reacción en cadena de la polimerasa para HHV-6, HHV-7, virus de Epstein-Barr (EBV) y citomegalovirus (CMV), hemocultivos y anticuerpos antinucleares (ANAs) [70].

Se recomienda realizar paraclínicos de seguimiento dos veces por semana en los cuales debe incluirse: hemoleucograma, AST, ALT, creatinina, lactato deshidrogenasa y otros, de acuerdo a los cambios encontrados en los paraclínicos iniciales [48].

\section{Prueba de parche}

Algunos estudios han implementado la prueba de parche como herramienta para la búsqueda del medicamento implicado en el desarrollo del DRESS [71,72]; sin embargo, no hay consenso sobre su utilización. Para esta prueba la sustancia en cuestión se pone en contacto con la piel y se observa posteriormente la reacción inflamación cutánea (véase figura 4) [73]. En un estudio donde se realizaron pruebas de parche a 56 pacientes con DRESS el resultado fue positivo en 18 de ellos (32,1\%), de los cuales 17 tuvieron un anticonvulsivante como medicamento implicado. En este estudio se concluyó que la prueba de parche es útil y segura como método para confirmar el medicamento culpable del DRESS en el caso de medicamentos antiepilépticos, pero con un valor limitado en el DRESS inducido por alopurinol [74]. 
A

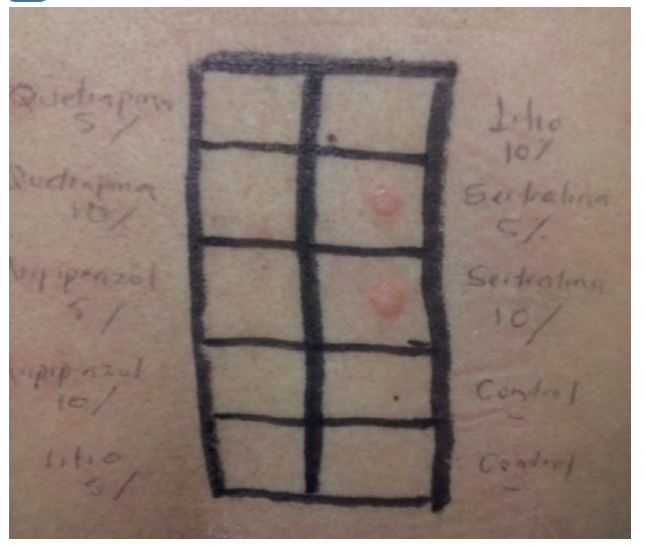

B

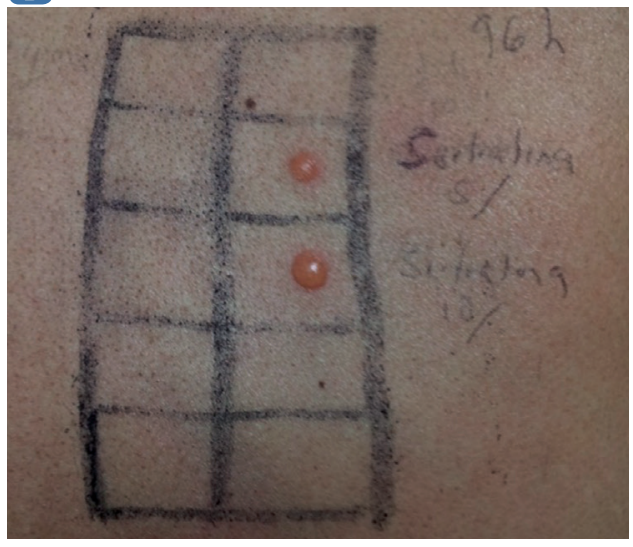

Figura 4. Paciente de 45 años con síndrome de DRESS en el contexto de consumo de litio y sertralina. Se le realizó prueba de parche con quetiapina en petrolato al $5 \%$ y $10 \%$, litio en petrolato al $5 \%$ y $10 \%$, sertralina en petrolato al 5\% y $10 \%$. A. lectura a las 48 horas. B. Lectura a las 96 horas, positivo para sertralina. Cortesía del servicio de Alergología Clínica de la IPS Unversitaria - Universidad de Antioquia. Medellín, Colombia.

\section{Tratamiento}

El reconocimiento rápido del agente causal y la suspensión de este es el paso más importante en el manejo de los pacientes con DRESS. El tratamiento del DRESS se ha basado durante muchos años en la utilización de corticosteroides sistémicos (dosis igual o equivalentes a 1,0-1,5 mg/ $\mathrm{kg} / \mathrm{día}$ de prednisolona). Estos deben ser reducidos paulatinamente posteriores a la normalización clínica y paraclínica. El tiempo total de tratamiento debe ser de tres a seis meses, con el propósito de evitar recaídas [75]. También se ha recomendado el uso de metilprednisolona en pulsos (30 mg/kg vía intravenosa por tres días), inmunoglobulina intravenosa y plasmaféresis o la combinación de estas terapias. Se debe evitar las terapias inmunosupresoras ya que incrementan el riesgo de infecciones y sepsis [48].

Se recomienda para el manejo terapéutico [48]:

- En ausencia de signos de severidad: esteroides tópicos (potencia alta), emolientes y anti-histamínicos.

- En presencia de signos de severidad: esteroides sistémicos, evaluación multidisciplinaria.

- Con signos severos y compromiso vital: esteroides sistémicos asociado a inmunoglobulina intravenosa a una dosis de $2 \mathrm{~g} / \mathrm{kg}$ por cinco días y evaluación por el grupo multidisciplinario.

- En presencia de signos de severidad con confirmación de reactivación viral: esteroides en combinación con antivirales (ganciclovir). 


\section{Pustulosis exantemática generalizada aguda}

\section{Generalidades}

La pustulosis exantemática generalizada aguda (PEGA) es una reacción cutánea severa causada por medicamentos e infecciones agudas; es una reacción pustulosa y se considera miembro de las «dermatosis neutrofílicas» [76]. Esta enfermedad fue inicialmente descrita por Baker y Ryan en 1968 como psoriasis pustular exantemática, pero el término actual fue introducido en 1980 por C. Beylot, un dermatólogo francés [77].

\section{Epidemiología}

Esta reacción pustulosa tiene una incidencia de uno a cinco casos por millón por año, sin predilección por algún grupo etéreo o género. Se considera una enfermedad autolimitada [77]; sin embargo, en pacientes ancianos con enfermedades crónicas se han descrito tasas de mortalidad entre $1 \%$ y $2 \%$ [78].

\section{Etiología}

El desarrollo de esta reacción se ha asociado con medicamentos en el $90 \%$ de los casos [77], donde los más reportados como agentes causales son las aminopenicilinas, las quinolonas, la hidroxicloroquina, las sulfonamidas, la terbinafina, el diltiazem, el ketoconazol y el fluconazol. Los agentes infecciosos como el parvovirus humano B19, Chlamydia pneumoniae, citomegalovirus, virus del Epstein-Barr, virus de la hepatitis $\mathrm{B}$ y Mycoplasma pneumoniae también se han relacionado con la entidad pero de forma menos frecuente [79]. Se han descrito casos de pustulosis exantemática generalizada aguda por metales pesados como el mercurio, suplementos dietarios, quimioterapia, radiación y terapia PUVA (psoraleno y luz ultravioleta A) [77].

\section{Fisiopatología}

Se sugiere que la pustulosis exantemática generalizada aguda es una enfermedad mediada por células T. Después de la exposición al agente causal las células presentadoras de antígenos presentan el antígeno en el contexto del complejo mayor de histocompatibilidad a las células $\mathrm{T} \mathrm{CD}^{+}$y $\mathrm{CD} 8^{+}$que causa su activación específica. Una vez activadas estas células proliferan y migran a la dermis y epidermis [78]. El linfocito $\mathrm{T} C D 8^{+}$específico usa perforinas y granzima $\mathrm{B}$ y mecanismos de inducción de la apoptosis de los queratinocitos a través de la vía FAS/FAS-L, lo que lleva a la destrucción tisular y formación de vesículas epidérmicas [77].

Durante la fase inicial de la enfermedad las vesículas están compuestas principalmente por células $\mathrm{T} \mathrm{CD}^{+}{ }^{+}$específicas y queratinocitos. Estas células liberan 
altas cantidades de la citoquina quimiotáctica de neutrófilos CXCL8, la cual facilita el reclutamiento de neutrófilos a las vesículas y la posterior formación de pústulas estériles [79].

Los análisis de las células T CD4+ específicas de los pacientes con pustulosis exantemática generalizada aguda muestran un predominio de producción de citoquinas del perfil Th1, como el factor estimulante de colonias de granulocitos y macrófagos (GM-CSF), el interferón-y (INF- $\gamma$ ) y el TNF- $\alpha$, las cuales actúan dando una mayor supervivencia a los neutrófilos. Por su parte, la liberación de eotaxinas/CCL11 y RANTES se relaciona con la eosinofilia observada en el $30 \%$ de los casos de pustulosis exantemática generalizada aguda [77].

Además, las células Th17 podrían desempeñar un papel en el desarrollo de la pustulosis exantemática generalizada aguda mediante la liberación de IL-17 e IL-22, las cuales tienen un efecto sinérgico sobre la producción de CXCL8 por parte de los queratinocitos [79]. Otro posible mecanismo es la producción de complejos antígeno-anticuerpo que son inducidos por medicamentos o infecciones, los cuales activan el sistema de complemento y causan quimiotaxis de los neutrófilos [80].

\section{Presentación clínica}

Las características típicas incluyen una erupción cutánea aguda, con pústulas estériles, eritema y edema acompañado de fiebre. La mayoría de las lesiones inician en áreas intertriginosas o en la cara. Los pacientes describen una sensación de quemazón o prurito. El compromiso de mucosas puede ser hasta del $20 \%$, pero usualmente es leve y limitado a una localización (la mayoría oral). EI promedio de inicio de las pústulas es de 48 horas después de la introducción del medicamento [79].

El cuadro clínico está asociado a leucocitosis con predominio de neutrófilos. También se puede encontrar leve eosinofilia, la cual suele estar presente en el $30 \%$ de los pacientes. Aproximadamente el $20 \%$ de los casos de pustulosis exantemática generalizada aguda tienen compromiso de otros órganos, generalmente leve y caracterizado por la reducción de la depuración de creatinina, elevación de las transaminasas hepáticas, derrame pleural bilateral e hipoxemia. Las pústulas resuelven espontáneamente entre los cuatro a diez días, con una leve descamación [78].

\section{Diagnóstico}

El diagnóstico está basado en cinco criterios clínicos y paraclínicos. El estudio europeo de reacciones adversas cutáneas severas (EuroSCAR; del inglés, European Study of Severe Cutaneous Adverse Reactions) publicó un sistema de puntuación para definir los cuadros clínicos probables, posibles y definitivos de pustulosis 
exantemática generalizada aguda. Este sistema ayuda a la estandarización del diagnóstico (véase tabla 2) [79].

La utilización de la prueba de parche y la prueba de transformación de linfocitos se han desarrollado para confirmar el diagnóstico y el medicamento implicado $[77,81]$.

Respecto a los diagnósticos diferenciales se deben tener en cuenta la psoriasis pustular, pústulas subcorneales e impétigo bulloso [78].

\section{Tratamiento}

La principal medida terapéutica de la pustulosis exantemática generalizada aguda es la remoción del agente causal; sin embargo, debido a que se trata de una entidad autolimitada no es necesario un tratamiento específico. Los antipiréticos se pueden utilizar como tratamiento sintomático [52]. El tratamiento con corticosteroides sistémicos ha sido correlacionado con disminución de la estancia hospitalaria [78]. La evolución en la mayoría de los pacientes es satisfactoria [52].

\section{Conclusiones}

Las reacciones severas cutáneas a medicamentos representan un reto diagnóstico y terapéutico. La identificación temprana de los síntomas y de las alteraciones en las pruebas de laboratorio permite disminuir la morbilidad y la mortalidad de los pacientes. Aún faltan estudios para identificar las mejores opciones terapéuticas pues actualmente la base del tratamiento es el retiro del agente causal.

Tabla 2. Sistema de puntuación del grupo de estudio EuroSCAR validado para la pustulosis exantemática generalizada aguda

Características

Puntuación

Morfología

Pústulas:

Típica

Compatible

Insuficiente

Eriticiente

Eritema:

Típica

Compatible

Insuficiente

Insuficiente

Distribución

Típica

Compatible

Insuficiente

1

Descamación pospustular:

Sí

No/insuficiente

\section{Curso clínico}

Compromiso de mucosa:

Sí -2

No

0

Inicio agudo(<10 días):

Sí

No

$-2$

Resolución ( $<15$ días):

Sí 0

No

$-4$

Fiebre $\left(>38^{\circ} \mathrm{C}\right)$

Sí 1

No

Neutrofilia $\left(>7.000 / \mathrm{mm}^{3}\right)$ :

$\begin{array}{ll}\text { Sí } & 1 \\ \text { No } & 0\end{array}$

$\begin{array}{ll}\text { Histología } & -10 \\ \text { Otras enfermedades } & 0 \\ \text { Histología no representativa } & 1 \\ \text { Exocitosis de neutrófilos } & 2 \\ \text { Pústulas subcorneales o intraepidér- } & 3 \\ \text { micas con edema papilar } & \\ \text { Espongiosis subcórnea o pústulas } \\ \text { intraepidérmicas con edema papilar } \\ \text { Interpretación: } \\ \text { <0: No pustulosis exantemática generalizada aguda } \\ \text { 1-4:Posible } \\ \text { 5-7: Probable } \\ \text { 8-12: Definitivo }\end{array}$




\section{Bibliografía}

1. Hoetzenecker W, Nageli M, Mehra ET, Jensen AN, Saulite I, Schmid-Grendelmeier $\mathbf{P}$, et al. Adverse cutaneous drug eruptions: current understanding. Semin Immunopathol 2016; 38: 75-86.

2. Marzano AV, Borghi A, Cugno $\mathbf{M}$. Adverse drug reactions and organ damage: The skin. Eur J Intern Med 2016; 28: 17-24.

3. Martin T, Li H. Severe cutaneous adverse drug reactions: a review on epidemiology, etiology, clinical manifestation and pathogenesis. Chin Med J (Engl) 2008; 121: 756-761.

4. Wooten JM. Adverse drug reactions: Part I. South Med J 2010; 103: 1025-1028; quiz 1029.

5. Letko E, Papaliodis DN, Papaliodis GN Daoud YJ, Ahmed AR, Foster CS. Stevens-Johnson syndrome and toxic epidermal necrolysis: a review of the literature. Ann Allergy Asthma Immunol 2005; 94: 419-436; quiz 436-418, 456.

6. Mockenhaupt $M$, Viboud $C$, Dunant $A$, Naldi L, Halevy S, Bouwes Bavinck JN, et al. Stevens-Johnson syndrome and toxic epidermal necrolysis: assessment of medication risks with emphasis on recently marketed drugs. The EuroSCAR-study. J Invest Dermatol $2008 ; 128$ : 35-44.

7. Serrano-Reyes C, Escobar-Valencia MF, Cardona-Villa R. Reacciones severas de hipersensibilidad a medicamentos. En: Cardona-Villa R, Serrano-Reyes C, eds. Alergia: abordaje clínico, diagnóstico y tratamiento. Bogotá D.C., Colombia: Editorial Médica Panamericana; 2010: 572-580.

8. Pichler WJ. Immune mechanism of drug hypersensitivity. Immunol Allergy Clin North Am 2004; 24: 373-397, v-vi.

9. Schwartz RA, McDonough PH, Lee BW. Toxic epidermal necrolysis: Part I. Introduction, history, classification, clinical features, systemic manifestations, etiology, and immunopathogenesis. J Am Acad Dermatol 2013; 69: 173 e171-113; quiz 185-176.

10. Browne BJ, Edwards B, Rogers RL. Dermatologic emergencies. Prim Care 2006; 33: 685-695, vi.

11. Harr T, French LE. Severe cutaneous adverse reactions: acute generalized exanthematous pustulosis, toxic epidermal necrolysis and Stevens-Johnson syndrome. Med Clin North Am 2010; 94: 727-742, x.

12. Creamer D, Walsh SA, Dziewulski P, Exton LS, Lee HY, Dart JK, et al. U.K. guidelines for the management of Stevens-Johnson syndrome/toxic epidermal necrolysis in adults
2016. Br J Dermatol 2016; 174: 1194-1227.

13. Mockenhaupt $\mathbf{M}$. The current understanding of Stevens-Johnson syndrome and toxic epidermal necrolysis. Expert Rev Clin Immunol 2011; 7: 803-813; quiz 814-805.

14. Patterson $\mathbf{R}$, Miller $\mathbf{M}$, Kaplan $\mathbf{M}$, Doan T, Brown J, Detjen $\mathbf{P}$, et al. Effectiveness of early therapy with corticosteroids in Stevens-Johnson syndrome: experience with 41 cases and a hypothesis regarding pathogenesis. Ann Allergy 1994; 73: 27-34.

15. Patterson R, Grammer LC, Greenberger PA, Lawrence ID, Zeiss CR, Detjen PF, et al. Stevens-Johnson syndrome (SJS): effectiveness of corticosteroids in management and recurrent SJS. Allergy Proc 1992; 13: 8995

16. Hsu DY, Brieva J, Silverberg NB, Silverberg JI. Morbidity and Mortality of Stevens-Johnson Syndrome and Toxic Epidermal Necrolysis in United States Adults. J Invest Dermatol 2016; 136: 1387-1397.

17. Bastuji-Garin S, Rzany B, Stern RS, Shear NH, Naldi L, Roujeau JC. Clinical classification of cases of toxic epidermal necrolysis, Stevens-Johnson syndrome, and erythema multiforme. Arch Dermatol 1993; 129: 9296.

18. Downey A, Jackson C, Harun N, Cooper A. Toxic epidermal necrolysis: review of pathogenesis and management. J Am Acad Dermatol 2012; 66: 995-1003.

19. Schalock PC, Dinulos JG. Mycoplasma pneumoniae-induced Stevens-Johnson syndrome without skin lesions: fact or fiction? ] Am Acad Dermatol 2005; 52: 312-315.

20. Gerull R, Nelle M, Schaible T. Toxic epidermal necrolysis and Stevens-Johnson syndrome: a review. Crit Care Med 2011; 39: 1521-1532.

21. Chung WH, Hung SI, Hong HS, Hsih MS, Yang LC, Ho HC, et al. Medical genetics: a marker for Stevens-Johnson syndrome. Nature 2004; 428: 486.

22. Illing PT, Vivian JP, Purcell AW, Rossjohn J, McCluskey J. Human leukocyte antigen-associated drug hypersensitivity. Curr Opin Immunol 2013; 25: 81-89.

23. Hung SI, Chung WH, Liou LB, Chu CC, Lin M, Huang HP, et al. HLA-B*5801 allele as a genetic marker for severe cutaneous adverse reactions caused by allopurinol. Proc Natl Acad Sci U S A 2005; 102: 4134-4139.

24. Kaniwa N, Saito $\mathbf{Y}$, Aihara $\mathbf{M}$, Matsunaga K, Tohkin M, Kurose $\mathbf{K}$, et al. HLA-B locus in 
Japanese patients with anti-epileptics and allopurinol-related Stevens-Johnson syndrome and toxic epidermal necrolysis. Pharmacogenomics 2008; 9: 1617-1622.

25. Lonjou C, Borot $\mathbf{N}$, Sekula P, Ledger N, Thomas L, Halevy $\mathbf{S}$, et al. A European study of HLA-B in Stevens-Johnson syndrome and toxic epidermal necrolysis related to five high-risk drugs. Pharmacogenet Genomics 2008; 18: 99-107.

26. Tassaneeyakul $\mathbf{W}$, Jantararoungtong $\mathbf{T}$, Chen P, Lin PY, Tiamkao S, Khunarkornsiri $\mathbf{U}$, et al. Strong association between HLA-B*5801 and allopurinol-induced Stevens-Johnson syndrome and toxic epidermal necrolysis in a Thai population. Pharmacogenet Genomics 2009; 19: 704-709.

27. Cheung YK, Cheng SH, Chan EJ, Lo SV, Ng MH, Kwan P. HLA-B alleles associated with severe cutaneous reactions to antiepileptic drugs in Han Chinese. Epilepsia 2013; 54: 1307-1314.

28. Nassif A, Bensussan A, Boumsell L, Deniaud $A$, Moslehi $H$, Wolkenstein $P$, et al. Toxic epidermal necrolysis: effector cells are drug-specific cytotoxic T cells. J Allergy Clin Immunol 2004; 114: 1209-1215.

29. Tohyama M, Hashimoto K. Immunological mechanisms of epidermal damage in toxic epidermal necrolysis. Curr Opin Allergy Clin Immunol 2012; 12: 376-382.

30. Pierard GE, Paquet $\mathbf{P}$. Facing up to toxic epidermal necrolysis. Expert Opin Pharmacother 2010; 11: 2443-2446.

31. Chung WH, Hung SI, Yang JY, Su SC, Huang SP, Wei CY, et al. Granulysin is a key mediator for disseminated keratinocyte death in Stevens-Johnson syndrome and toxic epidermal necrolysis. Nat Med 2008; 14: 1343-1350.

32. Takahashi R, Kano Y, Yamazaki Y, Kimishima M, Mizukawa $\mathbf{Y}$, Shiohara T. Defective regulatory $T$ cells in patients with severe drug eruptions: timing of the dysfunction is associated with the pathological phenotype and outcome. J Immunol 2009; 182: 80718079.

33. Abe $\mathbf{R}$. Immunological response in Stevens-Johnson syndrome and toxic epidermal necrolysis. J Dermatol 2015; 42: 42-48.

34. Wheatley LM, Plaut M, Schwaninger JM, Banerji A, Castells M, Finkelman FD, et al. Report from the National Institute of Allergy and Infectious Diseases workshop on drug allergy. J Allergy Clin Immunol 2015; 136: 262-271 e262.

35. Roujeau JC. Immune mechanisms in drug allergy. Allergol Int 2006; 55: 27-33.
36. Morales ME, Purdue GF, Verity SM, Arnoldo BD, Blomquist PH. Ophthalmic Manifestations of Stevens-Johnson Syndrome and Toxic Epidermal Necrolysis and Relation to SCORTEN. Am J Ophthalmol 2010; 150: 505510 e501.

37. Lim VM, Do A, Berger TG, Nguyen AH, DeWeese J, Malone JD, et al. A decade of burn unit experience with Stevens-Johnson Syndrome/Toxic Epidermal Necrolysis: Clinical pathological diagnosis and risk factor awareness. Burns 2016; 42: 836-843.

38. Wolkenstein P, Chosidow O, Flechet ML, Robbiola O, Paul M, Dume L, et al. Patch testing in severe cutaneous adverse drug reactions, including Stevens-Johnson syndrome and toxic epidermal necrolysis. Contact Dermatitis 1996; 35: 234-236.

39. Hassoun-Kheir N, Bergman $\mathbf{R}$, Weltfriend $\mathbf{S}$. The use of patch tests in the diagnosis of delayed hypersensitivity drug eruptions. Int J Dermatol 2016; 55: 1219-1224.

40. Zawodniak A, Lochmatter P, Yerly D, Kawabata T, Lerch M, Yawalkar N, et al. In vitro detection of cytotoxic $T$ and NK cells in peripheral blood of patients with various drug-induced skin diseases. Allergy 2010; 65: 376-384.

41. Mayorga C, Celik G, Rouzaire $\mathbf{P}$, Whitaker P, Bonadonna P, Rodrigues-Cernadas J, et al. In vitro tests for drug hypersensitivity reactions: an ENDA/EAACI Drug Allergy Interest Group position paper. Allergy 2016; 71: 1103-1134.

42. Kano Y, Hirahara K, Mitsuyama Y, Takahashi $\mathbf{R}$, Shiohara $\mathbf{T}$. Utility of the lymphocyte transformation test in the diagnosis of drug sensitivity: dependence on its timing and the type of drug eruption. Allergy 2007; 62: 1439-1444.

43. Garcia-Doval I, LeCleach $\mathbf{L}$, Bocquet $\mathbf{H}$, Otero XL, Roujeau JC. Toxic epidermal necrolysis and Stevens-Johnson syndrome: does early withdrawal of causative drugs decrease the risk of death? Arch Dermatol 2000; 136: 323-327.

44. Mehregan D, Van Vreede A, Goralewski M. Toxic epidermal necrolysis treatment and outcomes: a retrospective analysis of $10 \mathrm{pa}-$ tients treated with intravenous immunoglobulin. Int J Dermatol 2016; 55: e356-360.

45. Gaitanis G, Spyridonos P, Patmanidis K, Koulouras V, Nakos G, Tzaphlidou M, et al. Treatment of toxic epidermal necrolysis with the combination of infliximab and highdose intravenous immunoglobulin. Dermatology 2012; 224: 134-139.

46. Zarate-Correa LC, Carrillo-Gomez DC, Ramirez-Escobar AF, Serrano-Reyes C. 
Toxic epidermal necrolysis successfully treated with infliximab. J Investig Allergol Clin Immunol 2013; 23: 61-63.

47. Bastuji-Garin S, Fouchard N, Bertocchi M, Roujeau JC, Revuz J, Wolkenstein P. SCORTEN: a severity-of-illness score for toxic epidermal necrolysis. J Invest Dermatol 2000; 115: 149-153.

48. Walsh SA, Creamer D. Drug reaction with eosinophilia and systemic symptoms (DRESS): a clinical update and review of current thinking. Clin Exp Dermatol 2011; 36: 6-11.

49. Bocquet H, Bagot M, Roujeau JC. Drug-induced pseudolymphoma and drug hypersensitivity syndrome (Drug Rash with Eosinophilia and Systemic Symptoms: DRESS). Semin Cutan Med Surg 1996; 15: 250-257.

50. Chaiken BH, Goldberg BI, Segal JP. Dilantin sensitivity; report of a case of hepatitis with jaundice, pyrexia and exfoliative dermatitis. N Engl J Med 1950; 242: 897-898.

51. Kano Y, Shiohara T. The variable clinical picture of drug-induced hypersensitivity syndrome/drug rash with eosinophilia and systemic symptoms in relation to the eliciting drug. Immunol Allergy Clin North Am 2009; 29: 481-501.

52. Cacoub $\mathbf{P}$, Musette $\mathbf{P}$, Descamps V, Meyer O, Speirs C, Finzi L, et al. The DRESS syndrome: a literature review. Am J Med 2011; 124: 588-597.

53. Spriet S, Banks TA. Drug reaction with eosinophilia and systemic symptoms syndrome. Allergy Asthma Proc 2015; 36: 501-505.

54. Descamps V, Ben Said B, Sassolas B, Truchetet F, Avenel-Audran M, Girardin P, et al. [Management of drug reaction with eosinophilia and systemic symptoms (DRESS)]. Ann Dermatol Venereol 2010; 137: 703-708.

55. Skowron F, Bensaid B, Balme B, Depaepe L, Kanitakis J, Nosbaum A, et al. Drug reaction with eosinophilia and systemic symptoms (DRESS): clinicopathological study of 45 cases. J Eur Acad Dermatol Venereol 2015; 29: 2199-2205.

56. Ganeva M, Gancheva T, Lazarova R, Troeva J, Baldaranov I, Vassilev I, et al. Carbamazepine-induced drug reaction with eosinophilia and systemic symptoms (DRESS) syndrome: report of four cases and brief review. Int J Dermatol 2008; 47: 853-860.

57. Alfirevic A, Jorgensen AL, Williamson PR, Chadwick DW, Park BK, Pirmohamed M. HLA-B locus in Caucasian patients with carbamazepine hypersensitivity. Pharmacogenomics 2006; 7: 813-818.

58. Hsiao YH, Hui RC, Wu T, Chang WC, Hsih
MS, Yang CH, et al. Genotype-phenotype association between HLA and carbamazepine-induced hypersensitivity reactions: strength and clinical correlations. J Dermatol Sci 2014; 73: 101-109.

59. Genin E, Chen DP, Hung SI, Sekula $P$, Schumacher $M$, Chang PY, et al. HLA-A*31:01 and different types of carbamazepine-induced severe cutaneous adverse reactions: an international study and meta-analysis. Pharmacogenomics J 2014; 14: 281-288.

60. Sousa-Pinto B, Pinto-Ramos J, Correia C, Goncalves-Costa G, Gomes L, GilMata S, et al. Pharmacogenetics of abacavir hypersensitivity: A systematic review and meta-analysis of the association with HLA-B*57:01. J Allergy Clin Immunol 2015; 136: 1092-1094 e1093.

61. Descamps V , Valance A, Edlinger C, Fillet AM, Grossin M, Lebrun-Vignes B, et al. Association of human herpesvirus 6 infection with drug reaction with eosinophilia and systemic symptoms. Arch Dermatol 2001; 137: 301-304.

62. Tohyama M, Hashimoto K, Yasukawa M, Kimura H, Horikawa T, Nakajima K, et al. Association of human herpesvirus 6 reactivation with the flaring and severity of drug-induced hypersensitivity syndrome. $\mathrm{Br}$ J Dermatol 2007; 157: 934-940.

63. Seishima M, Yamanaka S, Fujisawa $T$, Tohyama M, Hashimoto K. Reactivation of human herpesvirus (HHV) family members other than HHV-6 in drug-induced hypersensitivity syndrome. Br J Dermatol 2006; 155: 344-349.

64. Bohan KH, Mansuri TF, Wilson NM. Anticonvulsant hypersensitivity syndrome: implications for pharmaceutical care. Pharmacotherapy 2007; 27: 1425-1439.

65. Husain Z, Reddy BY, Schwartz RA. DRESS syndrome: Part I. Clinical perspectives. J Am Acad Dermatol 2013; 68: 693 e691-614; quiz 706-698.

66. Criado PR, Criado RF, Avancini JM, Santi CG. Drug reaction with Eosinophilia and Systemic Symptoms (DRESS) / Drug-induced Hypersensitivity Syndrome (DIHS): a review of current concepts. An Bras Dermatol 2012; 87: 435-449.

67. Hirahara K, Kano Y, Mitsuyama Y, Takahashi $R$, Kimishima $M$, Shiohara $T$. Differences in immunological alterations and underlying viral infections in two well-defined severe drug eruptions. Clin Exp Dermatol 2010; 35: 863-868.

68. Choquet-Kastylevsky G, Intrator L, Chenal C, Bocquet H, Revuz J, Roujeau 
JC. Increased levels of interleukin 5 are associated with the generation of eosinophilia in drug-induced hypersensitivity syndrome. $\mathrm{Br}$ J Dermatol 1998; 139: 1026-1032.

69. Sultan SJ, Sameem F, Ashraf M. Drug reaction with eosinophilia and systemic symptoms: manifestations, treatment, and outcome in 17 patients. Int J Dermatol 2015; 54: 537-542.

70. Ortonne N, Valeyrie-Allanore L, Bastuji-Garin S, Wechsler J, de Feraudy $S$, Duong TA, et al. Histopathology of drug rash with eosinophilia and systemic symptoms syndrome: a morphological and phenotypical study. Br J Dermatol 2015; 173: 50-58.

71. Ghislain PD, Bodarwe AD, Vanderdonckt O, Tennstedt D, Marot L, Lachapelle JM. Drug-induced eosinophilia and multisystemic failure with positive patch-test reaction to spironolactone: DRESS syndrome. Acta Derm Venereol 2004; 84: 65-68.

72. Charfi O, Lakhoua G, Sahnoun R, Badri T, Daghfous R, El Aidli S, et al. DRESS Syndrome Following Levofloxacin Exposure With Positive Patch-test. Therapie 2015; 70: 547549.

73. Mahajan VK, Handa S. Patch testing in cutaneous adverse drug reactions: methodology, interpretation, and clinical relevance. Indian J Dermatol Venereol Leprol 2013; 79: 836-841.

74. Santiago F, Goncalo M, Vieira R, Coelho
S, Figueiredo A. Epicutaneous patch testing in drug hypersensitivity syndrome (DRESS). Contact Dermatitis 2010; 62: 47-53.

75. Husain Z, Reddy BY, Schwartz RA. DRESS syndrome: Part II. Management and therapeutics. J Am Acad Dermatol 2013; 68: 709 e701-709; quiz 718-720.

76. Lee HY, Chou D, Pang SM, Thirumoorthy T. Acute generalized exanthematous pustulosis: analysis of cases managed in a tertiary hospital in Singapore. Int J Dermatol 2010; 49: 507-512.

77. Speeckaert MM, Speeckaert R, Lambert J, Brochez L. Acute generalized exanthematous pustulosis: an overview of the clinical, immunological and diagnostic concepts. Eur J Dermatol 2010; 20: 425-433.

78. Sidoroff A, Halevy S, Bavinck JN, Vaillant L, Roujeau JC. Acute generalized exanthematous pustulosis (AGEP)--a clinical reaction pattern. J Cutan Pathol 2001; 28: 113-119.

79. Szatkowski J, Schwartz RA. Acute generalized exanthematous pustulosis (AGEP): A review and update. J Am Acad Dermatol 2015; 73: 843-848.

80. Mashiah J, Brenner S. A systemic reaction to patch testing for the evaluation of acute generalized exanthematous pustulosis. Arch Dermatol 2003; 139: 1181-1183.

81. Pichler WJ, Tilch J. The lymphocyte transformation test in the diagnosis of drug hypersensitivity. Allergy 2004; 59: 809-820.

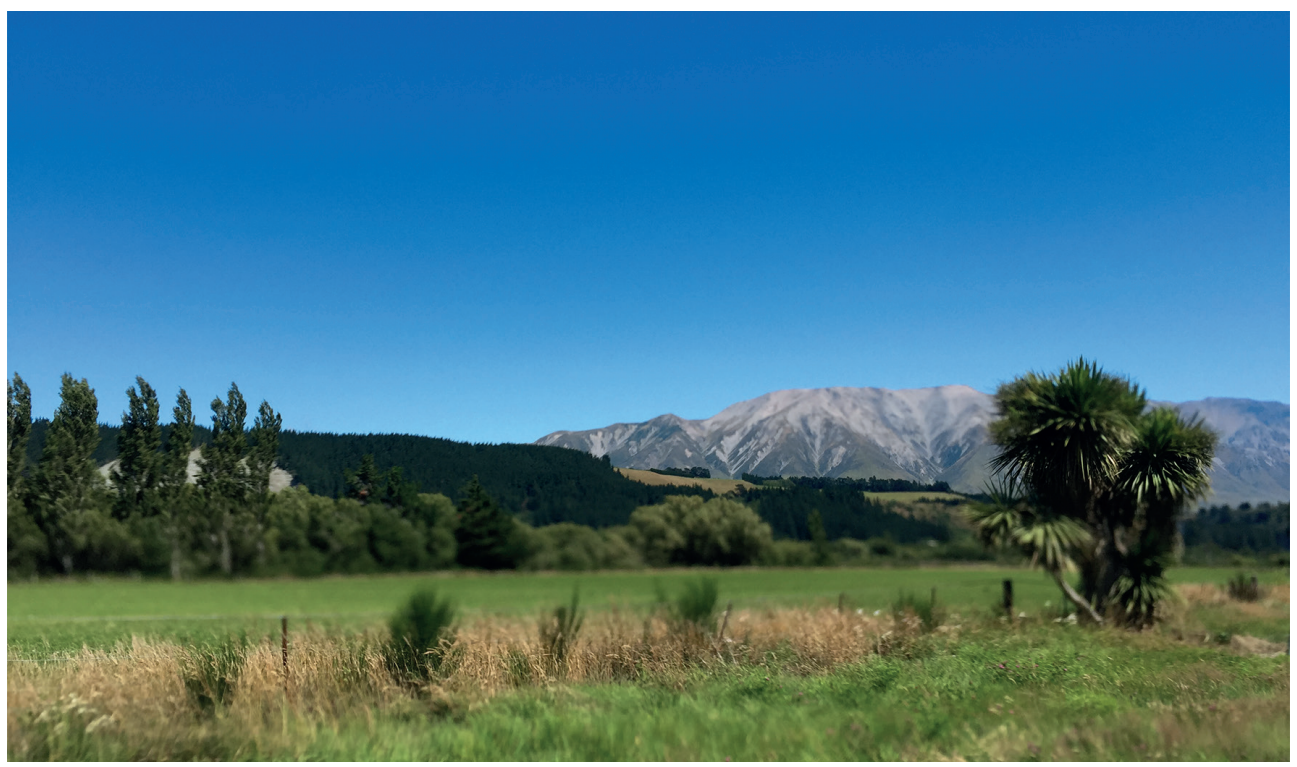

Lake Tekapo.

New Zealand.

Carlos Alberto Lozano M. carlos.lozano@iatm.com.co 